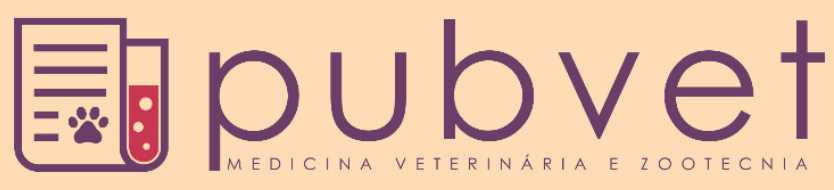

https://doi.org/10.31533/pubvet.v14n12a708.1-8

\title{
Febre amarela: entendimento da população sobre a zoonose comparado ao seu ensino
}

\author{
Ed Wilson Santos ${ }^{109}$, Geovanna Constantino de Almeida ${ }^{2}$, Giovanna Boari Debellis Mascaretti ${ }^{2} 9$, \\ Júlia Maria Serafim Pizol ${ }^{2} 9$
}

${ }^{1}$ Professor da faculdade de Medicina Veterinária, da Universidade Anhembi Morumbi, São Paulo, SP/Brasil

${ }^{2}$ Aluna da Faculdade de Medicina Veterinária, da Universidade Anhembi Morumbi, São Paulo, SP/Brasil

*Autora para correspondência: E-mail giovannavet01@gmail.com

Resumo. A febre amarela, uma zoonose de extrema importância para a saúde pública no Brasil e no mundo, é uma doença infecciosa, não contagiosa, causada por um vírus e transmitida pela picada de vetores. Existem duas formas de ocorrência desta enfermidade, sendo a febre amarela silvestre e a febre amarela urbana. Este estudo teve como objetivo principal avaliar o conhecimento da população sobre esta importante zoonose e, também, avaliar o nível de conhecimento dos estudantes de medicina veterinária comparado com os estudantes de outros cursos de nível superior. No geral, há discrepância entre os ensinos, em relação ao entendimento sobre a febre amarela, ocorrendo, ainda, na atualidade, equívocos no conhecimento da doença.

Palavras-chave: consciência, estudantes, febre amarela, zoonoses

\section{Yellow Fever: population knowledge about zoonosis compared to their teaching}

\begin{abstract}
Yellow fever is an extremely important zoonosis for public health in Brazil and worldwide. It is an infectious, non-contagious disease, caused by a virus and transmitted by the bite of vectors. There are two forms of the disease: sylvatic yellow fever and urban yellow fever. This study focused on evaluating the population's knowledge about this important zoonosis, and also to estimate the level of knowledge of veterinary medicine students compared to students of other higher education courses. In general, there is a discrepancy between the teachings, about the understanding of yellow fever, and there are still mistakes in the knowledge of the disease.
\end{abstract}

Keywords: Awareness, students, yellow fever, zoonosis

\section{Fiebre amarilla: conocimiento de la población sobre las zoonosis en comparación con su enseñanza}

Resumen. La fiebre amarilla, una zoonosis de extrema importancia para la salud pública en Brasil y en todo el mundo, es una enfermedad infecciosa, no contagiosa, causada por un virus y transmitida por la picadura de vectores. Hay dos formas de aparición de esta enfermedad, que son la fiebre amarilla salvaje y la fiebre amarilla urbana. Este estudio tuvo como objetivo principal evaluar el conocimiento de la población sobre esta importante zoonosis y, también, evaluar el nivel de conocimiento de los estudiantes de medicina veterinaria en comparación con los estudiantes de otros cursos de educación superior. En general, existe una discrepancia entre las enseñanzas, en relación con la comprensión de la fiebre amarilla, y aún existen errores en el conocimiento de la enfermedad.

Palabras clave: conciencia, estudiantes, fiebre amarilla, zoonosis 


\section{Introdução}

A febre amarela é uma doença causada por um arbovírus do gênero Flavivirus, família Flaviviridae, sendo classificada como uma enfermidade aguda, febril, não contagiosa, com período curto de duração de, no máximo, 12 (doze) dias. De gravidade variável, as manifestações clínicas podem indicar fases evolutivas da doença, a qual, em sua forma grave, apresentam sinais de insuficiência hepática e renal, que podem levar à morte. As regiões tropicais das Américas e da África são as responsáveis pelos surtos periódicos da doença, os quais variam e se mantém entre endêmica e enzoótica (Cavalcante \& Tauil, 2016).

A doença possui dois ciclos de transmissão, sendo eles: a febre amarela silvestre, a qual tem como o seu principal vetor os mosquitos do gênero Haemagogus e Sabethes, e a febre amarela urbana, que tem como vetor o mosquito Aedes Aegypti, o qual não promove mais a transmissão desde 1942 (Oliveira, 2017; Vasconcelos, 2002).

$\mathrm{O}$ vírus da febre amarela, identificado recentemente, gerou uma grande incógnita, pois havia uma incerteza se o vírus já estava presente na América antes do período escravagista. Desta forma, foram necessárias a realização de pesquisas relacionadas às ferramentas moleculares de amostras do vírus da febre amarela e, através deste estudo, foi constatado que o vírus teve sua origem na África, local que, quanto à epidemiologia, concentra-se mais de $90 \%$ dos casos notificados à Organização Mundial da Saúde (OMS) nos dias vigentes. Somado, ainda, ao ciclo urbano da doença, os índices do risco variam de acordo com a relação de pessoas vacinadas por região, sendo mais alto nas regiões em que há florestas e pessoas não vacinadas. Estas pessoas ficam mais expostas as picadas dos transmissores infectados pelo vírus (Vasconcelos, 2003).

Para o combate da febre amarela, a vacina disponível é a principal ferramenta de prevenção e controle da doença. Regularmente, nos serviços de saúde e durante a campanha da vacinação nos municípios que compõem a área com recomendação de vacina (ACRV), há uma satisfatória aplicação de doses da vacina. Porém, nas populações mais suscetíveis ao risco de adquirir a doença, como por exemplo os trabalhadores rurais, extrativistas, praticantes de pesca, turismo rural, de aventura e ecológico, e viajantes que se deslocam de áreas livres para áreas de risco, constatando-se uma divergência de cobertura na aplicação das vacinas e, também, nas estratégias para o combate, casos e surtos esporádicos que ainda acontecem (Brasil, 2015).

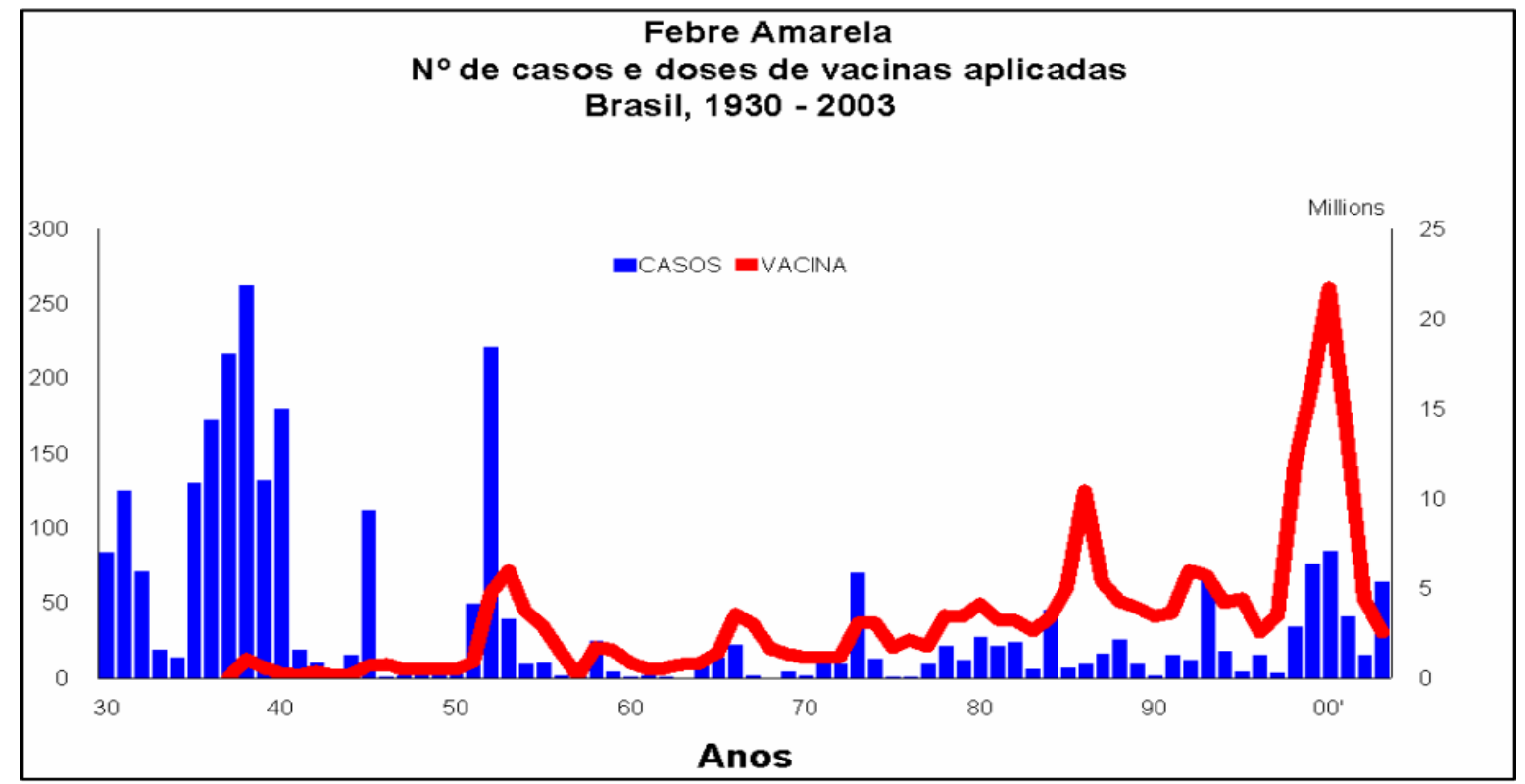

Gráfico 1. Febre amarela: $n^{\circ}$ de casos e doses de vacinas aplicadas no Brasil entre 1930 e 2003. Fonte: Ministério da Saúde

\section{Materiais e métodos}

Foi realizado um questionário online, através do sistema "Google Forms", por alunos do $9^{\circ}$ semestre de Medicina Veterinária, da Universidade Anhembi Morumbi (UAM), com o objetivo de examinar o 
grau de conhecimento da população acerca da febre amarela. As perguntas discutidas foram: "O que é zoonose?", "O que é a febre amarela?", "Como a febre amarela é transmitida?", "Assinale as alternativas nas quais você julga que expressam importância na vacinação", "Você é vacinado contra a febre amarela?", "Você sabe a importância da vacinação contra qualquer doença?", "Com as perguntas anteriores, como você descobriu as respostas?".

Desta pesquisa resultou-se um total de 152 respostas, as quais se dividem entre pessoas de diferentes idades, graus de escolaridade e gênero. Dentre os entrevistados, a escolaridade variou entre 06 (seis) pessoas que estudaram até ensino fundamental, 11 (onze) pessoas que estudaram até o ensino médio e 135 pessoas que estão cursando ou já finalizaram o ensino superior, sendo 39 (trinta e nove) estudantes de Medicina Veterinária ou Médicos Veterinários formados e 96 (noventa e seis) são formados ou estão cursando outros cursos de nível superior.

\section{Resultados e discussão}

\section{Em relação ao grau de escolaridade}

O Gráfico 2 demonstra a quantidade de acertos obtidos pelos entrevistados de diferentes graus de escolaridade (ensino fundamental, médio e superior), diante das seguintes questões: "O que é zoonose?", "O que é febre amarela?", "Como a febre amarela é transmitida?" e "Assinale as alternativas nas quais você julga que expressam importância na vacinação".

\section{Quantidade de acertos obtidos no questionário (\%)}

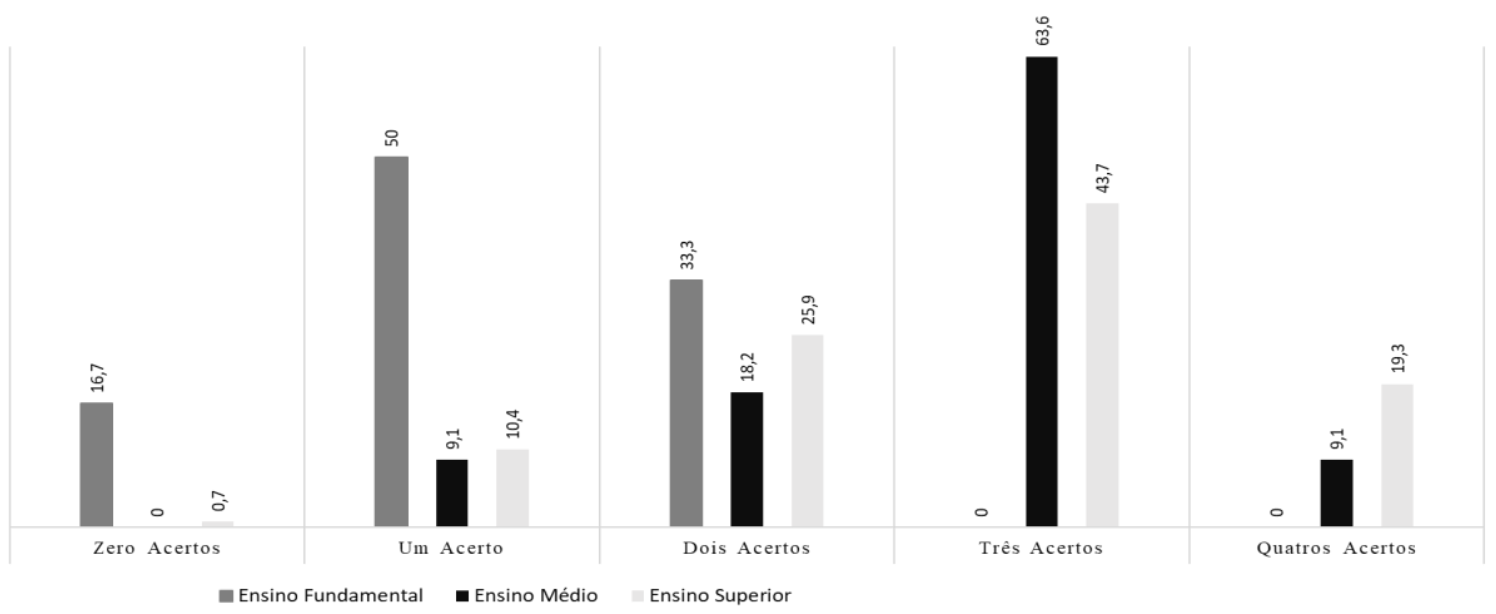

Gráfico 2. Quantidade de acertos obtidos no questionário.

A partir dos dados coletados constatou-se que as pessoas que estudaram até o ensino fundamental possuem um menor entendimento sobre a febre amarela, pois obtiveram a menor média de acertos. Em um total de 04 (quatro) perguntas, a porcentagem de acertos dividiu-se em: 16,7\% de zero acertos, 50\% com um acerto e 33,3\% com dois acertos. Assim, foi possível concluir que não foi abordado o assunto de zoonoses para os alunos de ensino fundamental entrevistados. A mesma conclusão se dá em Carvalho e Mayorga (2016), dos setenta (70) alunos do ensino fundamental entrevistados, 97\% (68/70) responderam haver desconhecimento sobre o tema e apenas 3\% (02/70) declararam já ter ouvido falar sobre a abordagem do assunto zoonoses. Assim, independente do termo habitualmente aplicado, não está sendo ensinado de uma forma esclarecida para as crianças.

Dentre os estudantes de ensino médio não houve nenhuma resposta com zero acertos, enquanto que, no ensino superior houve uma porcentagem de $0,7 \%$ de zero acertos. Ao comparar a maior quantidade de acertos entre ensino médio e ensino superior, observou-se que o ensino superior teve 19,3\% respostas com 04 (quatro) acertos enquanto o ensino médio teve 9,1\% respostas com 04 (quatro) acertos.

Em relação as respostas do ensino médio, 63,6\% acertaram 03 (três) questões e apenas 9,1\% gabaritou o questionário, sendo que esta porcentagem corresponde a uma pessoa. A partir da análise de 
dados obtidos com a pesquisa, verificou-se que a questão de maior desconhecimento é "O que é zoonose?", o que leva a crer que, no tocante a febre amarela, o assunto foi bem absorvido pelos estudantes de ensino médio, porém o conceito de zoonose não deve ter sido abordado na escola dos entrevistados ou foi abordado de uma maneira ineficaz, pois a maioria não soube responder a esta questão.

Em resumo, zoonoses são infecções comuns ao homem e a outros animais e nem sempre este conhecimento atinge a sociedade, a qual está exposta a riscos constantes e, segundo Lima et al. (2010), é necessário a aplicação de ações que minimizem esses efeitos, como métodos de prevenção, controle ou erradicação de determinadas doenças. O Ministério da Saúde crê que as escolas são os ambientes propícios para trabalhar o entendimento e as mudanças de comportamento entre os jovens, pois eles assumem um importante papel de agentes multiplicadores. Desta forma, entende-se que é fundamental abordar temas que conceituam as zoonoses dentro das instituições de ensino.

\section{Em relação à formação de nível superior}

No formulário foram disponibilizadas 04 (quatro) alternativas para a questão "O que é zoonose?". Observa-se que, os estudantes do curso de Medicina Veterinária têm maior sapiência sobre o assunto de zoonoses, com $64,1 \%$ de acertos na questão "O que é zoonose", enquanto outros cursos tiveram 44,8\% de acertos, conforme demonstrado no Gráfico 3.

Este cenário era o previsto quando o formulário foi feito, visto que o curso de medicina veterinária possui em sua grade o tema zoonoses. Na avaliação sobre o conhecimento conceitual de zoonoses, por Junior (2013), em sua pesquisa, 44,4\% dos médicos veterinários e 42,2\% dos concluintes do curso de medicina veterinária souberam conceituar o termo apropriadamente. Em contrapartida, apenas 3,4\% dos médicos humanos e 12,9\% dos graduandos em medicina humana assinalaram de forma correta.

O que é zoonoses? (\%)
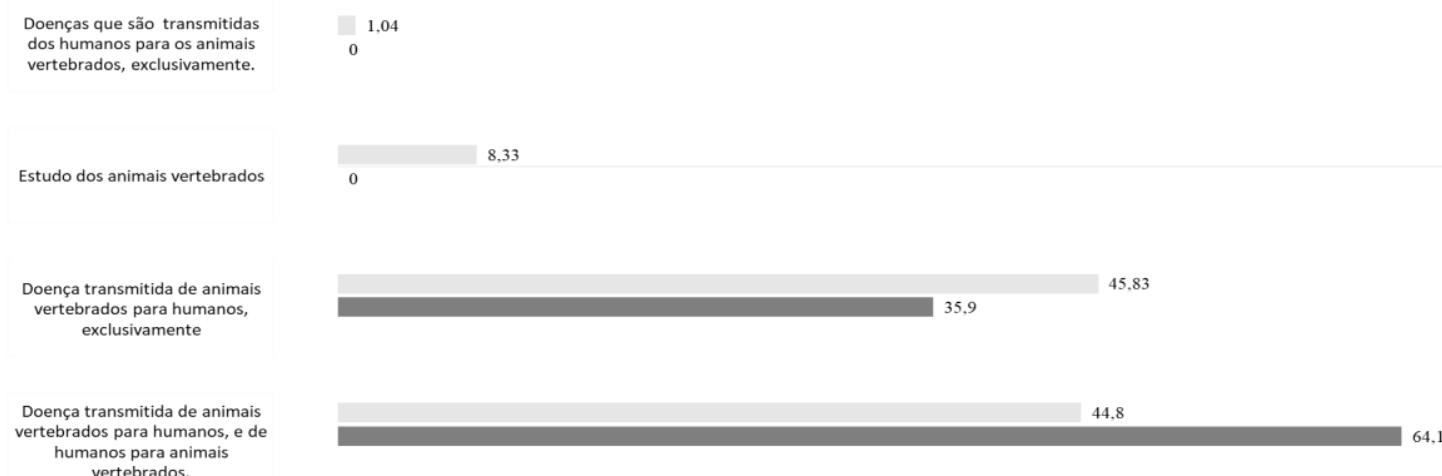

vertebrados.

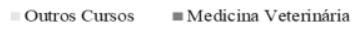

Gráfico 3. O que é zoonoses?

Dentre as respostas de medicina veterinária, $64,1 \%$ acertaram o conceito de zoonoses como sendo uma doença transmitida de animais vertebrados para humanos e de humanos para animais vertebrados; enquanto $35,9 \%$ se equivocaram ao classificar zoonose como uma doença transmitida de animais vertebrados para os humanos, exclusivamente.

Já entre os entrevistados pertencentes a outros cursos de ensino superior, apenas 44,8\% acertaram o conceito de zoonoses. Em contrapartida, $45,83 \%$ acreditam que zoonose é uma doença transmitida dos animais vertebrados para os humanos, exclusivamente; $8,33 \%$ acreditam que zoonose é o estudo dos animais vertebrados; e 1,04\% acreditam que zoonose é uma doença transmitida dos humanos para os animais vertebrados, exclusivamente. 
A partir da análise do Gráfico 4, observou-se que os estudantes de medicina veterinária possuem maior entendimento sobre a febre amarela, baseada na questão "O que é a febre amarela", com 97,4\% de acertos, enquanto os entrevistados de outros cursos de ensino superior obtiveram $82,3 \%$ de acertos.

O que é a febre amarela? (\%)

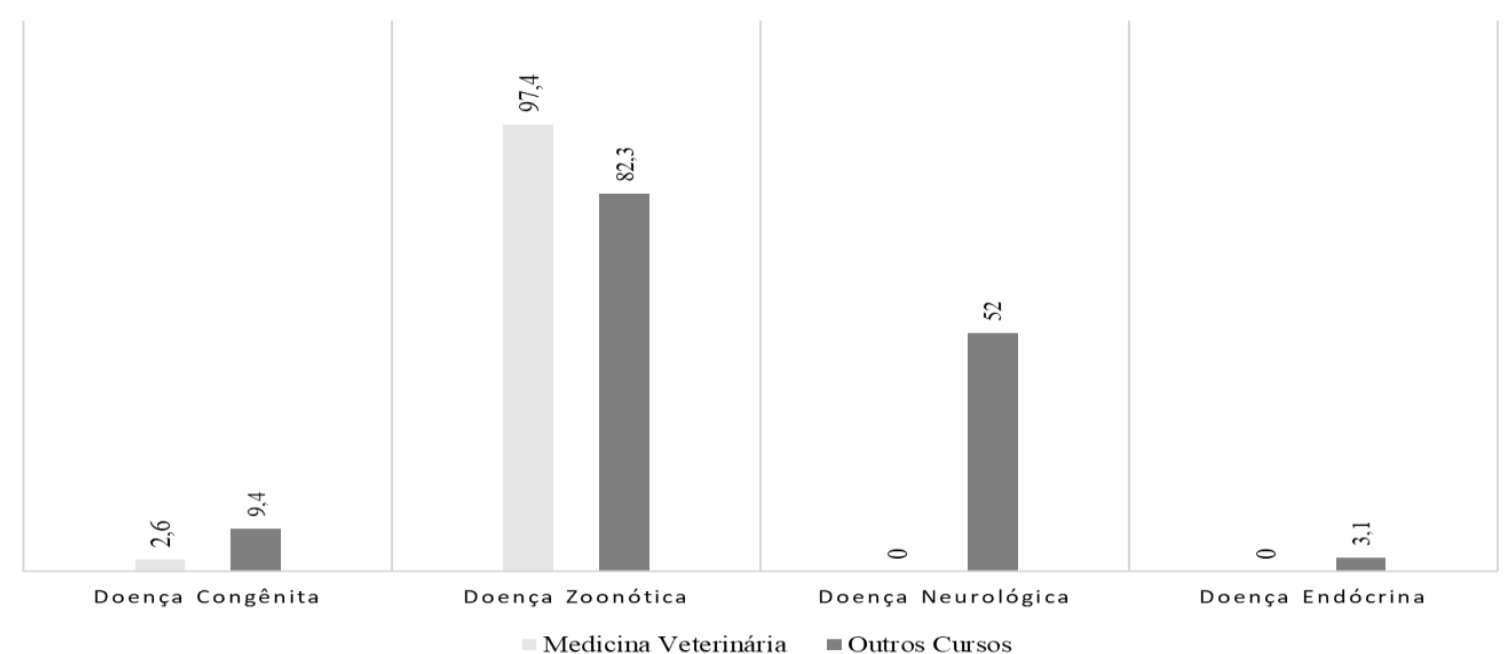

Gráfico 4. O que é febre amarela?

Dentre os estudantes de medicina veterinária entrevistados, apenas 2,6\%, correspondendo a uma pessoa, errou esta questão, afirmando erroneamente que a febre amarela é uma doença congênita. Em contrapartida, dentre os estudantes de outros cursos de nível superior, $17,7 \%$ erraram a questão; $9,4 \%$ acreditam que febre amarela é uma doença congênita; 5,2\% acreditam ser uma doença neurológica; e $3,1 \%$ acreditam ser uma doença endócrina.

Já com o resultado obtido pela questão "Como a febre amarela é transmitida", pontuado pelo Gráfico 5, observou-se que, dentro da medicina veterinária, houveram $46,2 \%$ de acertos, enquanto outros cursos obtiveram $45,83 \%$ de acertos.

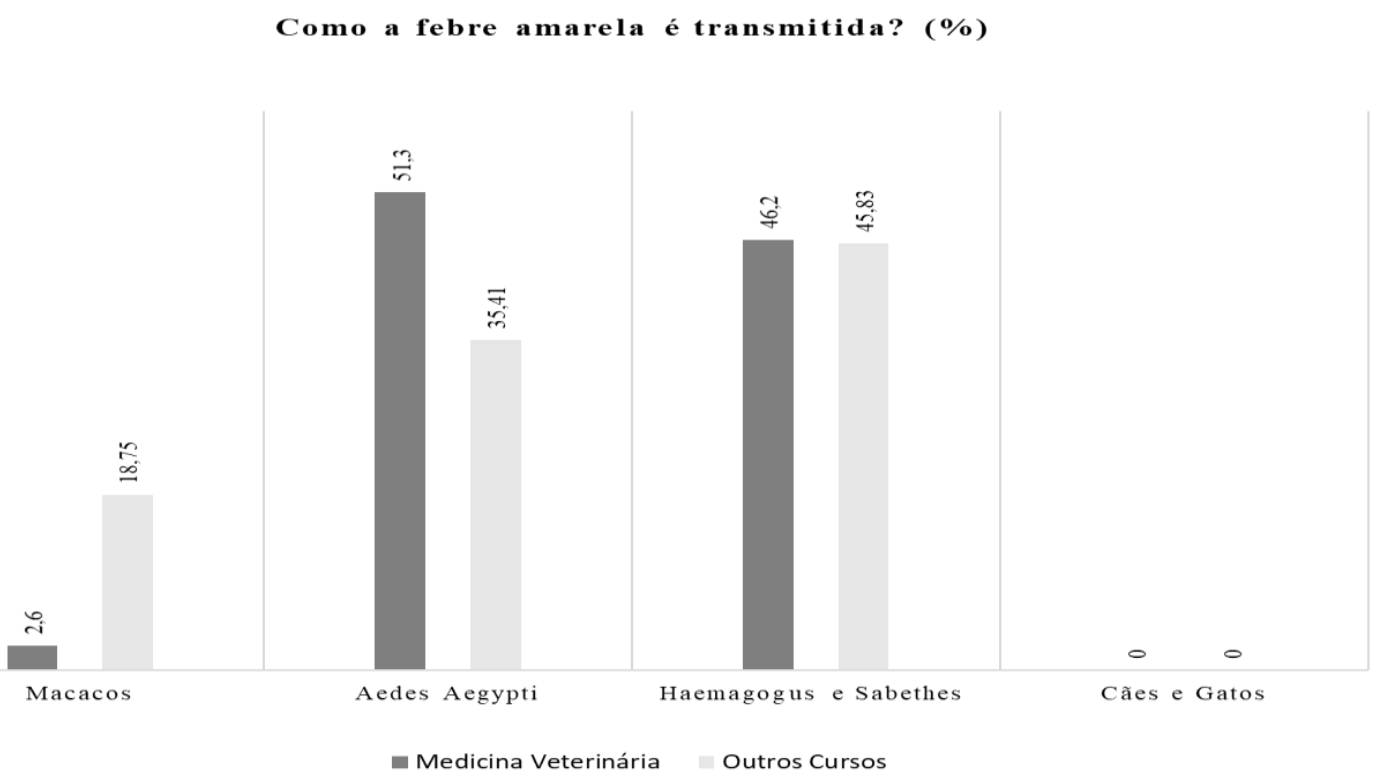

Gráfico 5. Como a febre amarela é transmitida? 
Dentro da medicina veterinária 51,3\% acreditam, erroneamente, que o Aedes aegypti é o transmissor da doença; enquanto 46,2\% acertaram a questão, afirmando que o Haemagogus e Sabethes são os vetores transmissores da febre amarela, já 2,6\% acreditam que a febre amarela é transmitida pelos macacos.

Dentre os entrevistados de outros cursos de ensino superior, 45,83\% acertaram a questão, assinalando Haemagogus e Sabethes, enquanto 35,41\% acreditam, erroneamente, que o Aedes aegypti é o transmissor da doença e, por fim, 18,75\% acreditam que os macacos são os transmissores desta enfermidade. Enfatizando a hipótese, pelo olhar da população, em Santos et al. (2019), 10,2\% acredita na transmissão direta da febre amarela, ao homem e a outros primatas, por macacos. Sugerindo, ainda, a morte dos mesmo como forma de prevenção.

A partir dos dados coletados, conclui-se que a maioria dos estudantes de medicina veterinária acreditam que o Aedes aegypti é o transmissor da febre amarela, enquanto dentro dos estudantes de outros cursos, o Aedes aegypti foi a segunda alternativa mais assinalada na questão. As mesmas controvérsias são encontradas em Santos et al. (2019), em que 56,8\% do público geral entrevistado, ainda, acredita que o Aedes aegypti é o principal vilão da atual epidemia.

Este equívoco não possui base pois, nos dias vigentes, o principal vetor da febre amarela urbana, o mosquito Aedes aegypti não promove mais a transmissão (Oliveira, 2017; Vasconcelos, 2002).

No formulário foram disponibilizadas 04 (quatro) alternativas para a questão "Assinale as alternativas nas quais você julga que expressam importância na vacinação". Analisando o Gráfico 6, conclui-se que a maioria dos questionados, tanto da Medicina Veterinária $(87,17 \%)$ como dos outros cursos $(88,5 \%)$, responderam que a importância da vacinação seria para "prevenir a ocorrência de doenças graves na população, podendo diminuir o número de mortes", sendo assim, assinalaram a resposta correta, demonstrando que sabem o quão essencial é a vacinação.

\section{Assinale as alternativas nas quais você julga que expressam importância na vacinação $(\%)$}

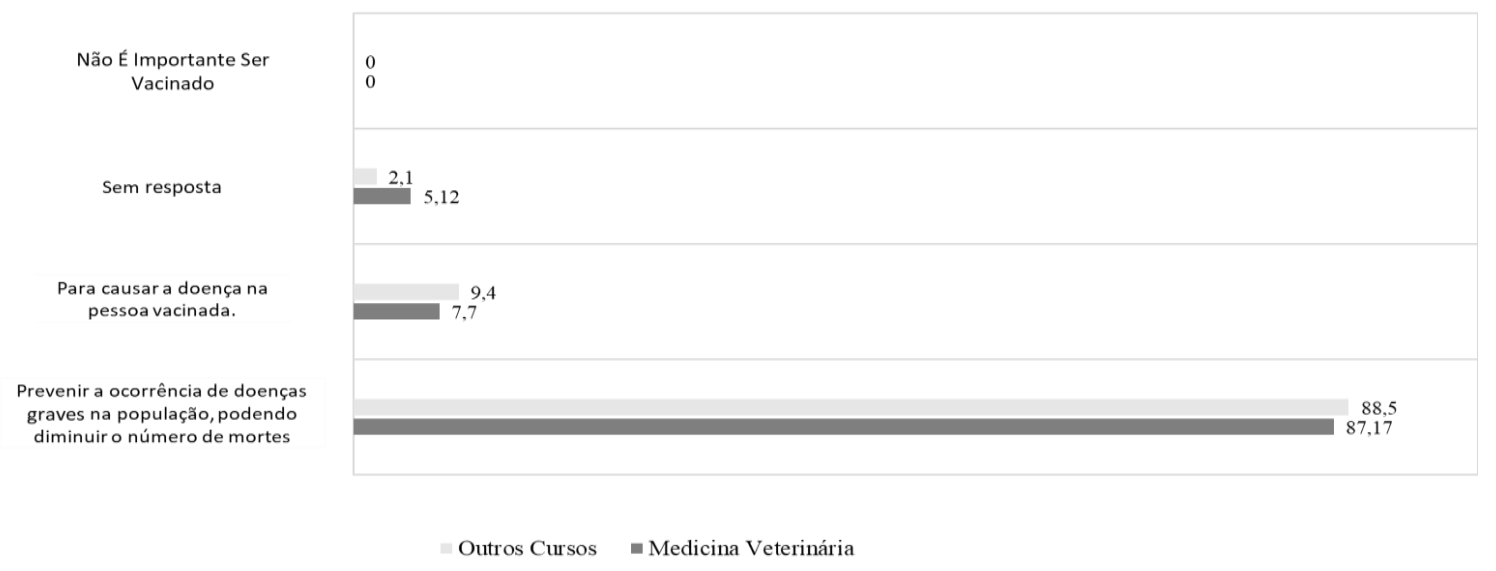

Gráfico 6. Assinale as alternativas nas quais você julga que expressam importância na vacinação.

Dentre os entrevistados, $7,7 \%$ de medicina veterinária e 9,4\% de outros cursos, acreditam, erroneamente, que a vacina causa a doença na pessoa vacinada.

\section{Em relação a importância da vacinação}

Segundo Brasil (2019), a reemergência do vírus foi marcada em áreas que não havia a recomendação de vacinação ou onde não se tinha registros de contaminação há décadas e, por consequência, a cobertura das vacinas eram baixas, sendo, atualmente, um desafio devido ao aumento de números de casos. A velocidade de transmissão se dá em detrimento de indivíduos que não estão vacinados, pois contribuem com a circulação do vírus.

Ao final do formulário, os entrevistados responderam duas breves questões sobre o conhecimento da importância da vacinação e se os mesmos são vacinados, conforme o Gráfico 7 abaixo. Porém, apesar 
de possuírem a consciência do quão importante é manter-se com a vacinação em dia, parte dos entrevistados não utilizam este conhecimento para se proteger. Em contrapartida, em Carvalho (2004), apenas $42,9 \%$ da população interrogada, responderam considerar a vacina uma medida protetora contra a febre amarela. Sendo assim, os planos de comunicação de prevenção da doença, com base na vacinação, devem ser implementados com a finalidade de alcançar a população afetada diretamente e com risco maior de contaminação, tendo como base diretrizes de conscientização sobre a importância da imunização.

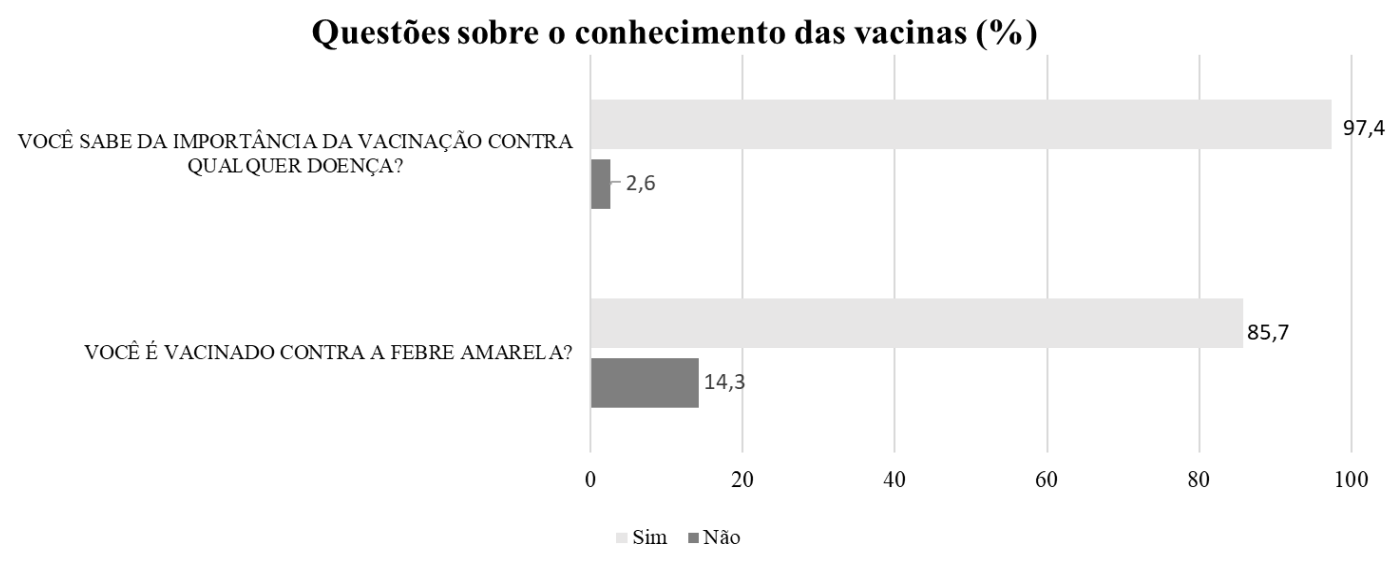

Gráfico 7. Onde adquiriu conhecimento das vacinas?

\section{Em relação ao conhecimento sobre a febre amarela}

No formulário também foi questionado por qual meio cada entrevistado adquiriu o conhecimento em relação a FA. A maioria das respostas apresentadas foi "conhecimento próprio" (41,64\%). Porém, observou que há um mal entendimento em relação a doença quando da realização de uma análise geral dos dados.

Observou-se, também, que as pessoas que responderam o questionário através do conhecimento transmitido pelas campanhas de conscientização feitas pelo governo $(17,47 \%)$ obtiveram um resultado melhor quando comparado com as pessoas que utilizaram do conhecimento próprio. Assim, conclui-se que as campanhas do governo possuem um alto grau de eficiência para aqueles que aderem. O Gráfico 8 demonstra o resultado de como as pessoas adquiriram conhecimento sobre a FA.

\section{Onde adquiriu conhecimento sobre a febre} amarela? (\%)

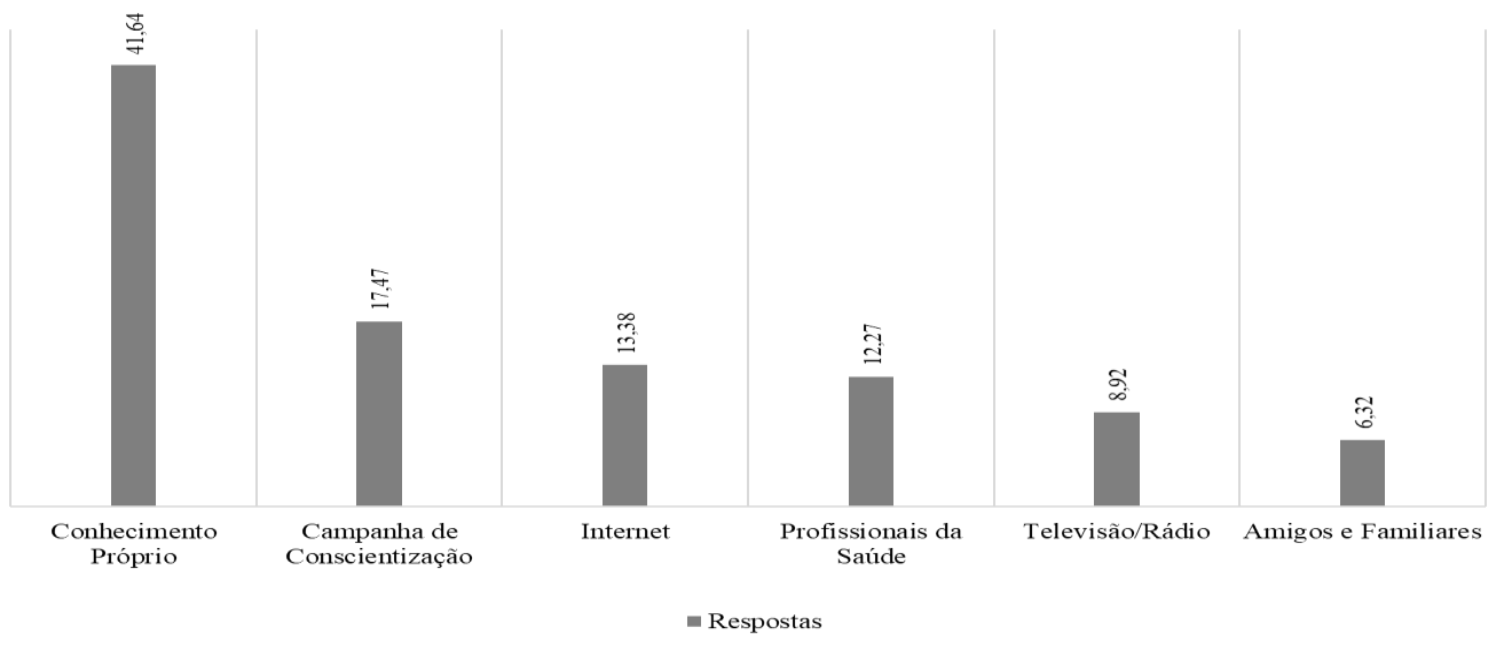

Gráfico 8. Onde adquiriu conhecimento sobre a febre amarela? 
Mediante o exposto, constatou-se que é de fundamental importância a antevisão da zoonose através de abordagens sobre o tema demonstrando o quanto a população está exposta a enfermidade e as consequências da reemergência da mesma dentro do país.

\section{Conclusão}

Em síntese, apesar das diversas campanhas de conscientização e de vacinação disponibilizadas pelo governo e, do conteúdo, teoricamente, fornecido aos alunos nas instituições de ensino, ainda há a ocorrência de diversos equívocos com relação a febre amarela e zoonoses no geral. Estas doenças estão presentes em grande escala no Brasil, portanto, a conscientização da população brasileira sobre assuntos como o quadro geral da doença, as formas de disseminação e prevenção e, ainda, os tratamentos, tornase fundamental, para que seja possível, futuramente, uma diminuição de casos no território brasileiro.

\section{Referências bibliográficas}

Brasil (2015). Reemergência da febre amarela silvestre no Brasil, 2014/2015: situação epidemiológica ea importância da vacinação preventiva e da vigilância intensificada no período sazonal. Secretaria de Vigilância Em Saúde, Ministério Da Saúde. Boletim Epidemiológico, 46(29).

Brasil (2019). Uma análise da situação de saúde com enfoque nas doenças imunopreveníveis e na imunização. In Epidemiológica, MS/SVE-Ministério da Saúde/Secretaria de Vigilância. Ministério da Saúde Brasília. http://portalarquivos2.saude.gov.br/images/pdf/2019/dezembro/05/Saude-Brasil2019-imunizacao.pdf

Carvalho M. A., França, E., Tavares, A. P., Martins, M. F. \& Malaguth, I. F. (2004). Conhecimento da população sobre transmissão e medidas de prevenção para dengue e febre amarela. Revista Médica de Minas Gerais. 14(1):8-12

Carvalho, G. F. \& Mayorga, G. R. S. (2016). Zoonoses e posse responsável de animais domésticos: percepção do conhecimento dos alunos em escolas no município de Teresópolis-RJ. Revista da Jornada de Pesquisa e Iniciação Cientifica. Vol. 1(1).

Cavalcante, K. R. L. J., \& Tauil, P. L. (2016). Características epidemiológicas da febre amarela no Brasil, 2000-2012. Epidemiologia e Serviços de Saúde, 25(1), 10-11. https://doi.org/10.5123/S167949742016000100002

Junior, J. R. R., Junior, J. W. P., Brandespim, D. F., Mota, R. A. \& Anderlini, G.A. (2013) Avaliação sobre o conhecimento de Zoonoses em profissionais e acadêmicos da Medicina e Medicina Veterinária na cidade de Maceió-Alagoas-Brasil. Revista Ciência Veterinária dos Trópicos. $16(1 / 2 / 3), 53-58$.

Lima, A. M. A., Alves, L. C., Faustino, M. A. G., \& Lira, N. M. S. (2010). Percepção sobre o conhecimento e profilaxia das zoonoses e posse responsável em pais de alunos do pré-escolar de escolas situadas na comunidade localizada no bairro de Dois Irmãos na cidade do Recife (PE). Ciência \& Saúde Coletiva, 15, 1457-1464.

Oliveira, W. A. (2017). Febre amarela no Brasil: um risco para a saúde pública. Revista de Saúde-RSF, $4(1)$.

Santos, E. W., Viana, A. C., Cyrino, G., Porto, K.; Genari, P., Souza, S. L. P. \& Pereira, C. A. D. (2019). Conhecimento sobre a transmissão e profilaxia da Febre Amarela no Município de São Paulo, Brasil.PubVet, 13(11), 150.

Vasconcelos, P. F. C. (2002). Febre amarela: reflexões sobre a doença, as perspectivas para o século XXI e o risco da reurbanização. Revista Brasileira de Epidemiologia, 5, 244-258.

Vasconcelos, P. F. C. (2003). Febre amarela. Revista Da Sociedade Brasileira de Medicina Tropical, $36(2), 275-293$.

Histórico do artigo:

Recebido: 18 de agosto, 2020.

Aprovado: 15 setembro, 2020.

Disponível online: 9 de novembro, 2020.
Licenciamento: Este artigo é publicado na modalidade Acesso Aberto sob a licença Creative Commons Atribuição 4.0 (CC-BY 4.0), a qual permite uso irrestrito, distribuição, reprodução em qualquer meio, desde que o autor e a fonte sejam devidamente creditados. 